\title{
Hyperprolactinemia in Thai children and adolescents with autism spectrum disorder treated with risperidone
}

This article was published in the following Dove Press journal:

Neuropsychiatric Disease and Treatment

22 January 2015

Number of times this article has been viewed

\author{
Yaowaluck Hongkaew ${ }^{1,2}$ \\ Nattawat Ngamsamut ${ }^{3}$ \\ Apichaya Puangpetch ${ }^{1,2}$ \\ Natchaya Vanwong ${ }^{1,2}$ \\ Pornpen Srisawasdi ${ }^{4}$ \\ Montri Chamnanphon ${ }^{1,2}$ \\ Bhunnada \\ Chamkrachchangpada ${ }^{3}$ \\ Teerarat Tan-kam ${ }^{3}$ \\ Penkhae Limsila ${ }^{3}$ \\ Chonlaphat Sukasem ${ }^{1,2}$ \\ 'Division of Pharmacogenomics \\ and Personalized Medicine, \\ Department of Pathology, Faculty \\ of Medicine, ${ }^{2}$ Laboratory for \\ Pharmacogenomics, Somdech \\ Phra Debaratana Medical Center \\ (SDMC), Ramathibodi Hospital, \\ Mahidol University, ${ }^{3}$ Yuwaprasart \\ Waithayopathum Child and \\ Adolescent Psychiatric Hospital, \\ Department of Mental Health \\ Services, Ministry of Public Health, \\ ${ }^{4}$ Division of Clinical Chemistry, \\ Department of Pathology, Faculty \\ of Medicine, Ramathibodi Hospital, \\ Mahidol University, Bangkok, Thailand
}

Correspondence: Chonlaphat Sukasem Division of Pharmacogenomics and Personalized Medicine, Department of Pathology, Faculty of Medicine, Ramathibodi Hospital, Mahidol University, Bangkok 10400, Thailand

Tel +66 2200433 I

Fax +6622004332

Email chonlaphat.suk@mahidol.ac.th

\begin{abstract}
Hyperprolactinemia is a common adverse effect observed in children with autism spectrum disorder (ASD) during pharmacotherapy with risperidone. The main aim of this study was to investigate important clinical factors influencing the prolactin response in risperidone-treated Thai ASD. A total of 147 children and adolescents (127 males and 20 females) aged 3-19 years with ASD received risperidone treatment $(0.10-6.00 \mathrm{mg} / \mathrm{day})$ for up to 158 weeks. Prolactin levels were measured by chemiluminescence immunoassay. The clinical data of patients collected from medical records - age, weight, height, body mass index, dose of risperidone, duration of treatment, and drug-use pattern - were recorded. Hyperprolactinemia was observed in 66 of 147 (44.90\%) subjects. Median prolactin level at the high doses $(24.00$, interquartile range [IQR] 14.30-29.20) of risperidone was significantly found to be higher than at the recommended (16.20, IQR 10.65-22.30) and low (11.70, IQR 7.51-16.50) doses of risperidone. There was no relationship between prolactin levels and duration of risperidone treatment. Dose-dependence is identified as a main factor associated with hyperprolactinemia in Thai children and adolescents with ASD treated with risperidone. This study suggests that risperidone treatment causes prolactin elevations and the effects of risperidone on prolactin are probably dose-related in pediatric patients.
\end{abstract}

Keywords: prolactin level, risperidone, autism spectrum disorders, Thai, hyperprolactinemia

\section{Introduction}

Autism spectrum disorder (ASD) is a lifelong developmental disability characterized by the three main symptoms of 1) significant impairments in social relationships, 2) language and communication deficits, and 3 ) restricted interests. ${ }^{1,2}$ Although autistic disorders are not very common, their current rates are higher than previously reported rates. The Autism and Developmental Disabilities Monitoring Network has estimated ASD prevalence to be around one in 68 children aged 8 years. ${ }^{3}$ Furthermore, the use of antipsychotic drugs has been increasingly suggested as a support to treatment of a variety of symptoms in autism. The US Food and Drug Administration (FDA) has approved the use of risperidone in children and adolescents aged 5-16 years old who have symptoms of irritability associated with autistic disorder. ${ }^{4,5}$ Although this antipsychotic can be effective in core-symptom reduction in youths with psychiatric disorders, it is also associated with mild adverse effects, especially hyperprolactinemia. ${ }^{6,7}$ Risperidone is one of the antipsychotics that most often induce hyperprolactinemia by blocking the dopamine $\mathrm{D}_{2}$ receptors (DRD2) in the anterior pituitary gland. ${ }^{6,8,9}$ Hyperprolactinemia can cause galactorrhea, amenorrhea, gynecomastia, hirsutism, loss of libido, impotence, and infertility. In addition, long-term hypogonadism owing 
to hyperprolactinemia has been associated with bone loss and osteoporosis..$^{8,10}$

Several studies have revealed that clinical characteristics, including sex, dosage, and duration of treatment, may have an effect on prolactin levels. ${ }^{11-13}$ Dose-related prolactin elevation has always been a main concern associated with the use of risperidone. In a previous study, increased levels in prolactin were noticed to be higher in the risperidone high-dose group than in either the risperidone low-dose group or placebo. ${ }^{13}$ In addition to prolactin-related adverse events, oligomenorrhea can also be found. ${ }^{13}$ Another cross-sectional retrospective study in risperidone-treated male youth reported that $68 \%$ of all patients had a prolactin level above the upper limit of normal, and risperidone also demonstrated a dose-dependent effect on prolactin levels. ${ }^{11}$ Although risperidone produced dose-related increases in serum prolactin levels, a significant relationship was not found between prolactin levels and the duration of treatment. ${ }^{11}$ Moreover, there is evidence that females show greater prolactin elevation than males when treated with risperidone. ${ }^{12,14}$

Hyperprolactinemia is the most common adverse effect of risperidone treatment in children with ASD. The primary aim of this study was to investigate the treatment effects of risperidone on prolactin levels in children and adolescents with ASD treated with risperidone in Thailand.

\section{Materials and methods Subjects}

This was a retrospective cross-sectional study. Subjects were 147 (127 boys and 20 girls) Thai children and adolescent outpatients aged 3-20 years who had been diagnosed with autism spectrum disorders according to the Diagnostic and Statistical Manual of Mental Disorders, fourth edition. All the subjects were recruited from the Yuwaprasart Waithayopathum Child and Adolescent Psychiatric Hospital, Samut Prakan, Thailand from May 2012 to April 2013. All subjects gave informed written consent to participate in the study, which was approved by the ethics committee of the Faculty of Medicine, Ramathibodi Hospital, Bangkok, Thailand. All participants receiving a risperidone-based regimen for at least 4 weeks were enrolled in this study. Clinical patient documentation for all samples included sex, age, weight, height, body mass index (BMI), daily dose of risperidone, duration of treatment, and concomitant therapy, such as monotherapy or combination therapy. All participants were advised to take the medication before the morning blood draw. Patients were excluded if they were receiving concomitant treatments that could potentially affect risperidone metabolism and prolactin elevation.
Age-group and risperidone-dose classification were the principal variables in this study. We compared these against serum prolactin levels in children (3-12 years) and adolescents (13-19 years), because at present only limited data are available concerning physiologic levels of prolactin during these periods of life. ${ }^{10}$ Recommended risperidone dosing for pediatric indications from the FDA was adjusted to categorize subjects into three groups, according to weight: low dose, recommended dose, and high dose. For most patients, the recommended starting dose of risperidone is $0.25-0.5 \mathrm{mg} /$ day if their body weight is less than $20 \mathrm{~kg}$ or $0.5-1 \mathrm{mg} /$ day if their body weight is greater than or equal to $20 \mathrm{~kg}$. If patients took less or more than FDA recommendation, this was classified as low or high dose, respectively.

\section{Serum prolactin measurement}

A fasting morning blood sample was analyzed with a chemiluminescence immunoassay system (Immulite 1000; Siemens Healthcare Diagnostics, Shanghai, People's Republic of China) in the laboratory of Yuwaprasart Waithayopathum Child and Adolescent Psychiatric Hospital. Hyperprolactinemia was defined as a prolactin level above percentile 97.5 on the basis of normative data for age and sex (according to Elmlinger et al). ${ }^{15}$

\section{Statistical analysis}

Discrepancies between data distribution and normal distribution were examined by the Kolmogorov-Smirnov test for each group. Descriptive statistics were used to describe the clinical characteristics of the subjects. Data are expressed as medians and interquartile ranges.

Fisher's exact test or Pearson's $\chi^{2}$ test was used to compare differences in patient characteristics between hyperprolactinemia and nonhyperprolactinemia in children and adolescents with autism. The nonparametric Kruskal-Wallis (comparisons among more than two groups) and Mann-Whitney rank tests (comparisons between two groups) were used to compare differences in median values (interquartile range). Accordingly, the nonparametric Spearman rank correlation test was used to measure relationships between two continuous random variables. SPSS version 18 for Windows was used to analyze all tests, which were two-sided, and $P$-values of less than 0.05 were considered statistically significant.

\section{Results}

A total of 147 participants had complete data and were included in the analysis. Table 1 lists the demographic and clinical characteristics of the sample. At the time of prolactin assessment, 
Table I Demographic and clinical characteristics of the children and adolescents with autism spectrum disorders in this study $(n=147)$

\begin{tabular}{ll}
\hline Characteristics & $\begin{array}{l}\text { Mean } \pm \text { standard deviation } \\
\text { (range) }\end{array}$ \\
\hline Age (years) & $9.52 \pm 3.72(3.42-19.33)$ \\
Weight $(\mathrm{kg})$ & $39.62 \pm 20.31(\mathrm{I} 1.70-108.00)$ \\
Height $(\mathrm{cm})$ & $136.54 \pm 20.73(88.00-185.00)$ \\
Body mass index $\left(\mathrm{kg} / \mathrm{m}^{2}\right)$ & $19.89 \pm 5.23(9.40-35.50)$ \\
Sex, $\mathbf{n}(\%)$ & $127(86.39 \%)$ \\
Male & $20(13.61 \%)$ \\
Female & $1.00 \pm 0.98(0.10-6.00)$ \\
Risperidone dose (mg/day) & \\
Risperidone dose, $\mathbf{n}(\%)$ & $15(10.20 \%)$ \\
Low dose & $97(65.99 \%)$ \\
Recommended dose & $35(23.81 \%)$ \\
High dose & $46.06 \pm 32.23(1.03-158.03)$ \\
Duration of treatment (months) & $62(42.18 \%)$ \\
Concomitant medication, $\mathrm{n}(\%)$ & \\
\hline
\end{tabular}

all autistic children and adolescents had means of age, weight, height, and BMI of 9.52 years, $39.62 \mathrm{~kg}, 136.54 \mathrm{~cm}$, and 19.89 $\mathrm{kg} / \mathrm{m}^{2}$, respectively. Almost all the participants were males (86.39\%). The mean risperidone dose of the subjects was $1 \mathrm{mg}$ / day or $0.03 \mathrm{mg} / \mathrm{kg} /$ day (standard deviations $0.93 \mathrm{mg} /$ day and $0.03 \mathrm{mg} / \mathrm{kg} /$ day, respectively), and mean duration of therapy was 46.06 months, respectively. Most patients were treated with risperidone at the FDA-recommended dose (65.99\%); the remaining patients with higher than FDA-recommended dose (23.81\%) and lower than FDA-recommended dose (10.20\%). The median serum prolactin concentration of the study was $16.60 \mathrm{ng} / \mathrm{mL}$ for all patients.

Sixty-six patients (44.90\%) had hyperprolactinemia: 64 (96.97\%) were male and two (3.03\%) female; $50(75.76 \%)$ were children and 16 (24.24\%) adolescents; 36 (54.55\%) were using only risperidone and 30 (45.45\%) were using concomitant medication; and four $(6.06 \%)$ were in the low-dose group, $38(57.58 \%)$ in the recommended-dose group, and 24 (36.36\%) in the high-dose group. The clinical characteristics of the patients were classified into two groups, according to the hyperprolactinemia $(n=66)$ and the non-hyperprolactinemia $(n=81)$. Using Pearson's $\chi^{2}$ test or Fisher's exact test of each parameter between two groups, the results showed that there was a statistically significant relationships between the presence of hyperprolactinemia and sex $(P=0.001)$ and risperidone-dose group $(P=0.004)$. However, there was no significant relationship in age-group and type of drug use found between patients with and without hyperprolactinemia, as summarized in Table 2.

For prescribed risperidone, the median concentrations of serum prolactin were $11.70 \mathrm{ng} / \mathrm{mL}(\mathrm{n}=15,10.20 \%)$, $16.20 \mathrm{ng} / \mathrm{mL}(\mathrm{n}=97,65.99 \%)$, and $24.00 \mathrm{ng} / \mathrm{mL}(\mathrm{n}=35$, $23.81 \%$ ) in the low-dose, recommended-dose, and high-dose groups, respectively. These findings showed that there were statistically significant differences in prolactin level among three groups $(P=0.002)$. The median prolactin level at the high dose was significantly higher than at the recommended dose and low dose (Table 3 and Figure 1).

This finding confirmed that prolactin levels were positively and significantly associated with risperidone dose $\left(r_{\mathrm{s}}=0.309, P<0.001\right)$, as shown in Figure 2. However, no statistical correlations were found between prolactin concentrations and age, weight, height, BMI, or duration of treatment in total patients (Table 4).

\section{Discussion}

To the best of our knowledge, this is the first study in a Thai and Asian population examining the frequency of

Table 2 Hyperprolactinemia in children and adolescents with autism spectrum disorders receiving risperidone

\begin{tabular}{|c|c|c|c|}
\hline & n (total I47) & Hyperprolactinemia (n=66), n (\%) & $P$-value \\
\hline Sex & & & $0.00 \mathrm{I}^{\mathrm{a}}$ \\
\hline Male & 127 & $64(50.39)$ & \\
\hline Female & 20 & $2(10.00)$ & \\
\hline Age-group & & & $0.638^{\mathrm{b}}$ \\
\hline Children ( $3-12$ years) & 114 & $50(43.86)$ & \\
\hline Adolescents ( $13-19$ years) & 33 & $16(48.48)$ & \\
\hline Drug regimen & & & $0.468^{\mathrm{b}}$ \\
\hline Single risperidone & 85 & $36(42.35)$ & \\
\hline Concomitant therapy & 62 & $30(48.39)$ & \\
\hline Dose of risperidone treatment & & & $0.004^{a}$ \\
\hline Low dose & 15 & $4(26.67)$ & \\
\hline Recommended dose & 97 & $38(39.18)$ & \\
\hline High dose & 35 & $24(68.57)$ & \\
\hline
\end{tabular}

Notes: aFisher's extract test; ${ }^{b} \chi{ }^{2}$ test. 
Table 3 Association between prolactin level $(\mathrm{ng} / \mathrm{mL})$ and categorical variables of clinical characteristics

\begin{tabular}{|c|c|c|c|}
\hline Clinical characteristics & n (total I47) & Prolactin level (ng/mL), median (IQR) & $P$-value \\
\hline Sex & & & $0.123^{\mathrm{a}}$ \\
\hline Male & 127 (86.39\%) & $17.60(10.90-35.08)$ & \\
\hline Female & $20(13.61 \%)$ & $15.90(10.39-18.03)$ & \\
\hline Age-group & & & $0.514^{a}$ \\
\hline Children & II 4 (77.55\%) & $16.50(10.73-32.70)$ & \\
\hline Adolescents & $33(22.45 \%)$ & $18.30(10.95-28.60)$ & \\
\hline Drug regimen & & & $0.270^{\mathrm{a}}$ \\
\hline Single risperidone & 85 (57.82\%) & $16.50(10.13-22.85)$ & \\
\hline Concomitant therapy & $62(42.18 \%)$ & $16.75(11.70-26.58)$ & \\
\hline Dose of risperidone treatment & & & $0.002^{\mathrm{b}}$ \\
\hline Low dose & $15(10.20 \%)$ & $1 \mathrm{I} .70(7.5 \mathrm{I}-\mathrm{I} 6.50)$ & \\
\hline Recommended dose & 97 (65.99\%) & $16.20(10.65-22.30)$ & \\
\hline High dose & $35(23.81 \%)$ & $24.00(14.30-29.20)$ & \\
\hline
\end{tabular}

Notes: aMann-Whitney U-test; ${ }^{\circ}$ Kruskal-Wallis test.

Abbreviation: $I Q R$, interquartile range.

hyperprolactinemia in children with ASD treated with risperidone. The high prevalence of hyperprolactinemia ( $44.90 \%$ of total patients) was found in this sample, which is broadly consistent with the frequency of risperidone-induced hyperprolactinemia found in pediatric populations studied by other investigators: 34 of $50(68 \%)$ by Stevens et al ${ }^{11}$ 53 of $107(50 \%)$ by Calarge et a ${ }^{16}$ and 23 of $49(47 \%)$ by Roke et al. ${ }^{17}$ Several reports have indicated that risperidone produced significantly greater increases of prolactin concentrations, as well as a higher frequency of hyperprolactinemia, than other antipsychotic drugs. ${ }^{11,18,19}$ Our results support the conclusions of previous hyperprolactinemia studies in children and adults that risperidone has a tendency to produce prolactin elevations.

The dose effect of risperidone on serum prolactin concentration was evident in this study. Risperidone produced

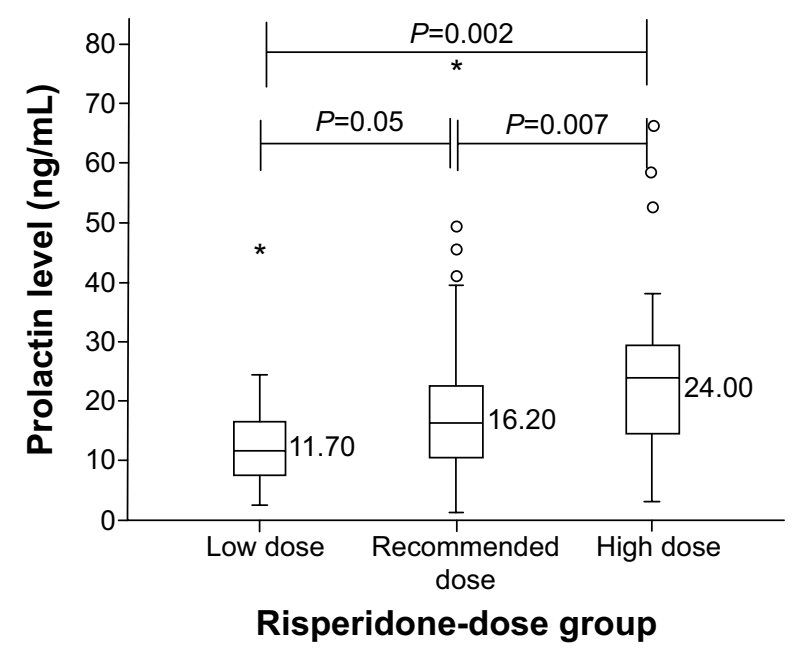

Figure I Association of prolactin levels and risperidone dose by group. Note: $* P=0.002$ (Kruskal-Wallis test). dose-related elevation of serum prolactin concentrations in children and adolescents with ASD (in terms of risperidonedose group and $\mathrm{mg} / \mathrm{day}$; Figures 1 and 2). This study is consistent with some of the literature on both pediatric and adult patients showing that risperidone exhibits a dose-dependent effect on prolactin levels. ${ }^{20,21}$ Another study in psychiatric children and adolescents discovered that patients taking a risperidone dose increased by $1 \mathrm{mg}$ /day may have raised mean prolactin levels by $3.6 \mathrm{ng} / \mathrm{mL}$ (analyzed data using a random-intercept linear model). ${ }^{7}$ Our findings indicate that this is an issue that clinicians need to consider in prolactin levels with patients on risperidone.

Reasons for correlations between prolactin concentrations and duration of treatment were not found, which may be explained by a difference in the duration of medication. Prolactin response tends to be more pronounced in the acute

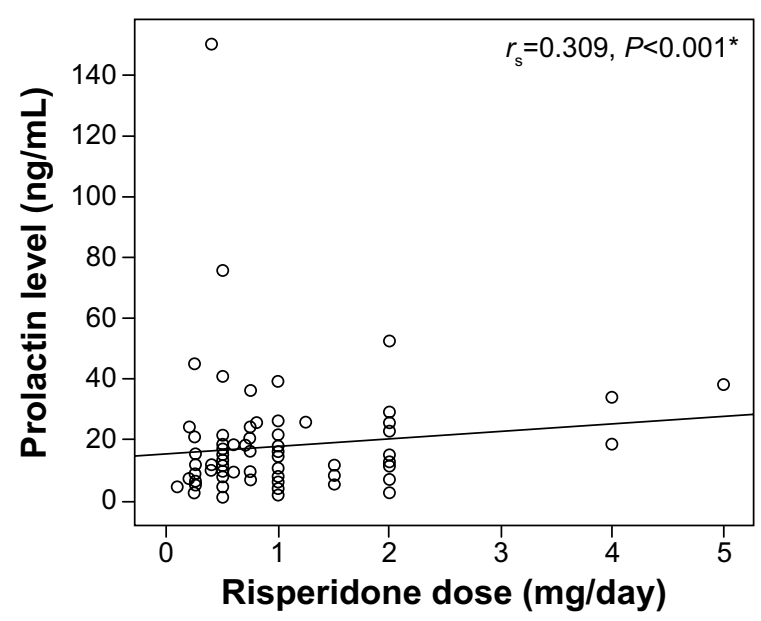

Figure 2 Association between serum prolactin levels and risperidone in 147 patients with autism spectrum disorder.

Note: *Spearman's correlation test. 
Table 4 Association between prolactin level and the continuous variables of clinical characteristics

\begin{tabular}{lll}
\hline Clinical characteristics & \multicolumn{2}{l}{ Prolactin level $(\mathrm{ng} / \mathrm{mL})$} \\
\cline { 2 - 3 } & $\begin{array}{l}\text { Correlation } \\
\text { coefficient }\left(\boldsymbol{r}_{\mathrm{s}}\right)\end{array}$ & P-value \\
\hline Age (years) & -0.012 & 0.885 \\
Weight $(\mathrm{kg})$ & -0.019 & 0.819 \\
Height $(\mathrm{cm})$ & 0.001 & 0.097 \\
Body mass index $\left(\mathrm{kg} / \mathrm{m}^{2}\right)$ & -0.032 & 0.700 \\
Risperidone dose $(\mathrm{mg} /$ day) & 0.309 & $<0.00 \mathrm{I}^{\mathrm{a}}$ \\
Duration of treatment (months) & -0.037 & 0.657 \\
\hline
\end{tabular}

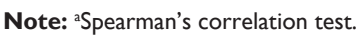

phase than in the chronic phase ${ }^{12}$ and the decreased tendency of some atypical agents compared to conventional agents. In our study of duration, treatment was followed up for a number of years (from 1 to 152 months), which failed to show a significant association between prolactin level and the length of drug treatment for risperidone. A similar study also indicated that a long interval of risperidone treatment did not indicate any statistically significant correlation between duration of treatment and prolactin level. ${ }^{11,22}$

This study has some limitations that should be taken into account when interpreting the results and should be addressed in future studies. First, the small number of patients in this study greatly limited comparisons, particularly in females. The FDA has notified that treatment with antipsychotic medications increases the risk of adverse effects, and several studies have confirmed that some medications are riskier than others. ${ }^{23-25}$ Children and adolescents with autism in this study have regularly undergone reassessment to adjust doses. Adverse effects also occurred less often than in adults.

In all cases, baseline prolactin levels prior to the initiation of antipsychotic therapy were not available for comparison, and no comparable group on another atypical antipsychotic agent was available. All participants were advised to take the medication any time before the morning blood collection. The study did not eliminate the influence of hormone levels associated with menstrual cycle phase in premenopausal females. Although prolactin levels were generalized to age and sex, the potential fluctuation of prolactin levels with the female menstrual cycle, in which prolactin response is associated with estrogen activity, should be borne in mind. Other genetic polymorphisms that might affect prolactin concentrations, including 5-hydroxytryptamine (serotonin) receptor $(H T R)$ and P-glycoprotein $(A B C B 1)$ genes, and also other CYP2D6 and DRD2 variants, were not investigated. This study did not comment on whether people had symptoms (such as amenorrhea or others mentioned earlier) as a result of the increase; it only reported that in the lab, prolactin levels were increased in the patient's blood. It should also be noted that lower doses can also cause serious adverse events. ${ }^{26}$

In conclusion, hyperprolactinemia was present in $44.90 \%$ (66 of 147) of patients. This study suggests that risperidone treatment causes prolactin elevations, and the effects of risperidone on prolactin are probably dose-related in pediatric patients. Prospective studies should include a larger patient sample population for risperidone-treated children and adolescents with autism. This information will be helpful to clinicians by providing significantly important clinical information to properly inform therapeutic practice and prevent sexual dysfunction consequently in autistic children treated with risperidone.

\section{Acknowledgments}

This research project was supported by 1) Mahidol University, 2) Khun Poom Foundation, a project under Her Royal Highness Princess Ubonratana Rajakanya Siriwatana Bhanawadee, 3) the National Research Council of Thailand, and 4) the Faculty of Medicine, Ramathibodi Hospital. The authors would specially like to thank the staff at Yuwaprasart Waithayopathum Child and Adolescent Psychiatric Hospital for their assistance. We are also grateful to all the children and adolescents with ASD who contributed to the study.

\section{Disclosure}

The authors report no conflicts of interest in this work.

\section{References}

1. American Psychiatric Association. Diagnostic and Statistical Manual of Mental Disorders. 5th ed. Washington: American Psychiatric Association; 2013.

2. Roke Y, van Harten PN, Buitelaar JK, Tenback DE, de Rijke YB, Boot AM. Antipsychotic-induced hyperprolactinemia and testosterone levels in boys. Horm Res Paediatr. 2012;77(4):235-240.

3. Developmental Disabilities Monitoring Network Surveillance Year 2010 Principal Investigators. Prevalence of autism spectrum disorder among children aged 8 years - autism and developmental disabilities monitoring network, 11 sites, United States, 2010. MMWR Surveill Summ. 2014;63(2):1-21.

4. Douglas-Hall P, Curran S, Bird V, Taylor D. Aripiprazole: a review of its use in the treatment of irritability associated with autistic disorder patients aged 6-17. J Cent Nerv Syst Dis. 2011;3:143-153.

5. Gagliano A, Germanò E, Pustorino G, et al. Risperidone treatment of children with autistic disorder: effectiveness, tolerability, and pharmacokinetic implications. J Child Adolesc Psychopharmacol. 2004; 14(1):39-47.

6. Agency for Healthcare Research and Quality. Therapies for Children With Autism Spectrum Disorders: A Review of the Research for Parents and Caregivers. Rockville (MD): AHRQ; 2011. 
7. Migliardi G, Spina E, D'Arrigo C, et al. Short- and long-term effects on prolactin of risperidone and olanzapine treatments in children and adolescents. Prog Neuropsychopharmacol Biol Psychiatry. 2009; 33(8):1496-1501.

8. Anderson GM, Scahill L, McCracken JT, et al. Effects of short- and long-term risperidone treatment on prolactin levels in children with autism. Biol Psychiatry. 2007;61(4):545-550.

9. Masi G, Cosenza A, Mucci M. Prolactin levels in young children with pervasive developmental disorders during risperidone treatment. JChild Adolesc Psychopharmacol. 2001;11(4):389-394.

10. Aklillu E, Kalow W, Endrenyi L, Harper P, Miura J, Ozdemir V. CYP2D6 and DRD2 genes differentially impact pharmacodynamic sensitivity and time course of prolactin response to perphenazine. Pharmacogenet Genomics. 2007;17(11):989-993.

11. Stevens JR, Kymissis PI, Baker AJ. Elevated prolactin levels in male youths treated with risperidone and quetiapine. J Child Adolesc Psychopharmacol. 2005;15(6):893-900.

12. Yasui-Furukori N, Saito M, Tsuchimine S, et al. Association between dopamine-related polymorphisms and plasma concentrations of prolactin during risperidone treatment in schizophrenic patients. Prog Neuropsychopharmacol Biol Psychiatry. 2008;32(6):1491-1495.

13. Kent JM, Kushner S, Ning X, et al. Risperidone dosing in children and adolescents with autistic disorder: a double-blind, placebo-controlled study. J Autism Dev Disord. 2013;43(8):1773-1783.

14. Hellings JA, Zarcone JR, Valdovinos MG, Reese RM, Gaughan E, Schroeder SR. Risperidone-induced prolactin elevation in a prospective study of children, adolescents, and adults with mental retardation and pervasive developmental disorders. J Child Adolesc Psychopharmacol. 2005;15(6):885-892.

15. Elmlinger MW, Kuhnel W, Ranke MB. Reference ranges for serum concentrations of lutropin (LH), follitropin (FSH), estradiol (E2), prolactin, progesterone, sex hormone-binding globulin (SHBG), dehydroepiandrosterone sulfate (DHEAS), cortisol and ferritin in neonates, children and young adults. Clin Chem Lab Med. 2002;40(11):1151-1160.

16. Calarge CA, Ellingrod VL, Acion L, et al. Variants of the dopamine D2 receptor gene and risperidone-induced hyperprolactinemia in children and adolescents. Pharmacogenet Genomics. 2009;19(5):373-382.
17. Roke Y, van Harten PN, Franke B, Galesloot TE, Boot AM, Buitelaar JK. The effect of the Taq1A variant in the dopamine D2 receptor gene and common CYP2D6 alleles on prolactin levels in risperidone-treated boys. Pharmacogenet Genomics. 2013;23(9):487-493.

18. Young RM, Lawford BR, Barnes M, et al. Prolactin levels in antipsychotic treatment of patients with schizophrenia carrying the DRD2*A1 allele. Br J Psychiatry. 2004;185:147-151.

19. Kinon BJ, Gilmore JA, Liu H, Halbreich UM. Prevalence of hyperprolactinemia in schizophrenic patients treated with conventional antipsychotic medications or risperidone. Psychoneuroendocrinology. 2003;28 Suppl 2:55-68.

20. Kleinberg DL, Davis JM, de Coster R, Van Baelen B, Brecher M. Prolactin levels and adverse events in patients treated with risperidone. J Clin Psychopharmacol. 1999;19(1):57-61.

21. Turrone P, Kapur S, Seeman MV, Flint AJ. Elevation of prolactin levels by atypical antipsychotics. Am J Psychiatry. 2002;159(1):133-135.

22. Buhagiar K, Cassar JR. Prolactin levels during long-term risperidone treatment in children and adolescents: a cross-sectional study. Ger $J$ Psychiatry. 2008;11(2):45-50.

23. Roke Y, Buitelaar JK, Boot AM, Tenback D, van Harten PN. Risk of hyperprolactinemia and sexual side effects in males 10-20 years old diagnosed with autism spectrum disorders or disruptive behavior disorder and treated with risperidone. JChild Adolesc Psychopharmacol. 2012;22(6):432-439.

24. Lemmon ME, Gregas M, Jeste SS. Risperidone use in autism spectrum disorders: a retrospective review of a clinic-referred patient population. J Child Neurol. 2011;26(4):428-432.

25. Bishop JR, Rubin LH, Reilly JL, Pavuluri MN, Sweeney JA. Risperidoneassociated prolactin elevation and markers of bone turnover during acute treatment. Ther Adv Psychopharmacol. 2012;2(3):95-102.

26. Peitl MV, Peitl V, Grahovac T, Pavlović E. Galactorrhea - side effect of risperidone in combination with depakine chrono in a patient with bipolar disorder. Psychiatr Danub. 2010;22(1):125-127.
Neuropsychiatric Disease and Treatment

\section{Publish your work in this journal}

Neuropsychiatric Disease and Treatment is an international, peerreviewed journal of clinical therapeutics and pharmacology focusing on concise rapid reporting of clinical or pre-clinical studies on a range of neuropsychiatric and neurological disorders. This journal is indexed on PubMed Central, the 'PsycINFO' database and CAS,

\section{Dovepress}

and is the official journal of The International Neuropsychiatric Association (INA). The manuscript management system is completely online and includes a very quick and fair peer-review system, which is all easy to use. Visit http://www.dovepress.com/testimonials.php to read real quotes from published authors. 